\title{
USE OF REFLECTIVE WRITING RUBRIC FOR ASSESSMENT IN DIABETES EDUCATION AND TRAINING
}

\author{
B. Lim, G.L. Png, Y.H. Lo, S. Goh. \\ St. Luke Hospital, Singapore
}

\section{Introduction}

Learning is an essential part for professional development and using reflective writing rubric for assessment and grading learners for diabetes education promotes learners to reflect through assessment information to yield meaningful insights about learning and help connect learners to the overall program goals.

Nurse educators from St. Luke Hospital (SLH) explored using reflective writing rubric concurrently with the post program evaluation of comprehensive diabetes education training for inpatient nursing staff. The course was designed to provide 10 didactic lectures, case studies and hands-on sessions on glucose testing and injection technique supported by a multi-disciplinary team of healthcare professionals comprising endocrinologist, diabetes educator, dietician, pharmacist, quality and safety director and sport medicine physician over 4 months in duration.

This study aims to describe the outcome of using reflective writing rubric for assessment and grading of diabetes education and training among nursing staff.

\section{Methodology}

A reflective learning evaluation criteria using rubric (RLER) was developed to use concurrent with the pre and post training evaluations. The rubric was formulated using three domains which comprises the content quality, the critical thinking and the structure. Scoring was performed using the rubric and assessed by two nurse educators. Nursing staff who had attended at least 4 education sessions were invited to participate in the RLER. Three questions were asked to reflect post learning - "what did you learn from the diabetes course training"; "why does it matter to you" and "what might/should be done better in our care setting" with RLER. The reflective writing rubric scoring was set at a maximum score of 30 marks. The post learning evaluation participation were by voluntary and identity of staff were anonymous.

\section{Results}

A total of 167 nurses attended the sessions. Only 84 (50\%) of nursing staff had completed at least 4 diabetes education sessions. The registered nurses were the highest in number participated in the reflective learning survey comparing to enrolled nurses and nursing aides (refer Figure 1). 91\% (RN: 47 EN: 22) reported they had achieved good/excellent on diabetes care and management knowledge in the post course training. (refer Figure 2 )

Figure 1

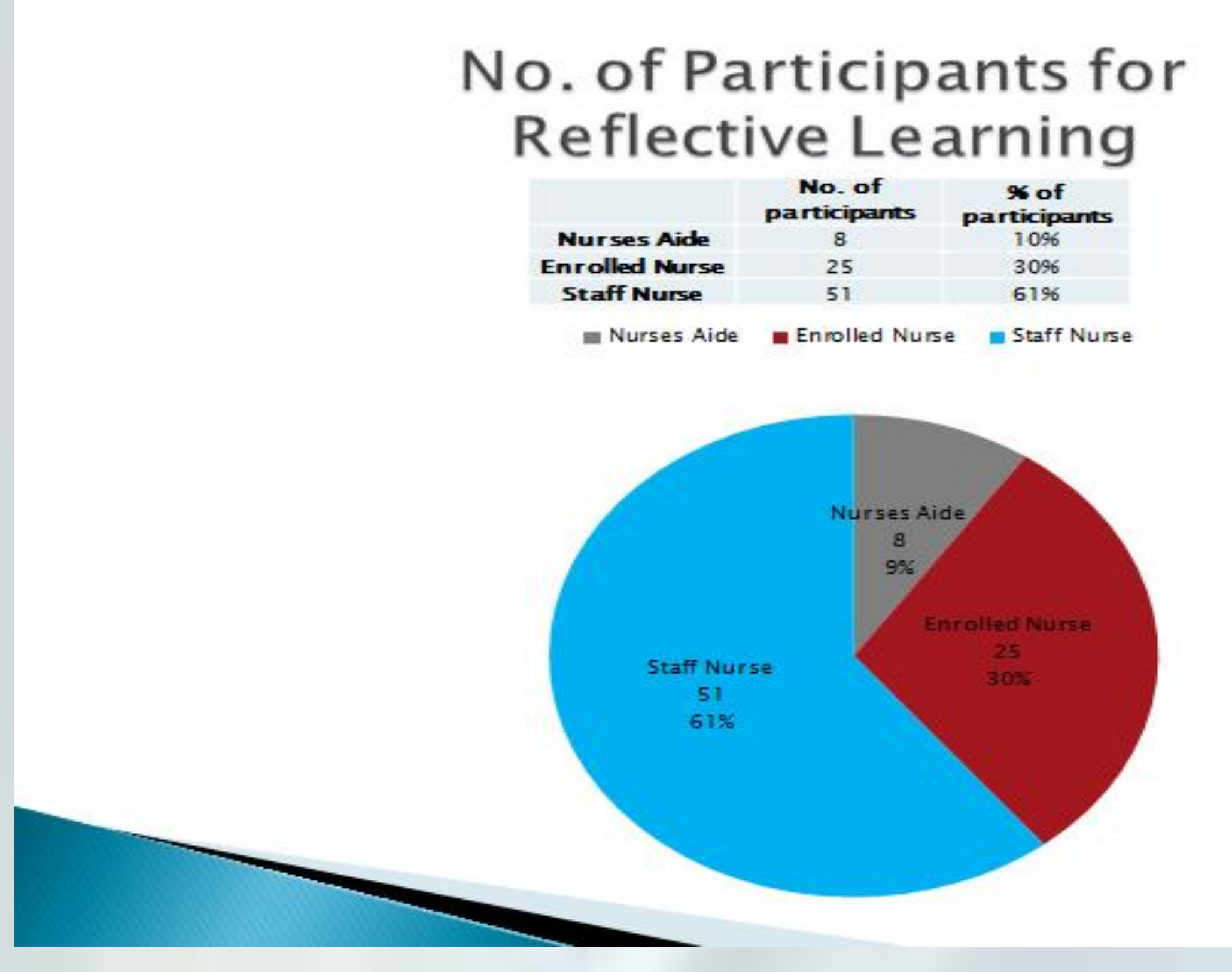

Figure 2

Reflective Scores from Participants
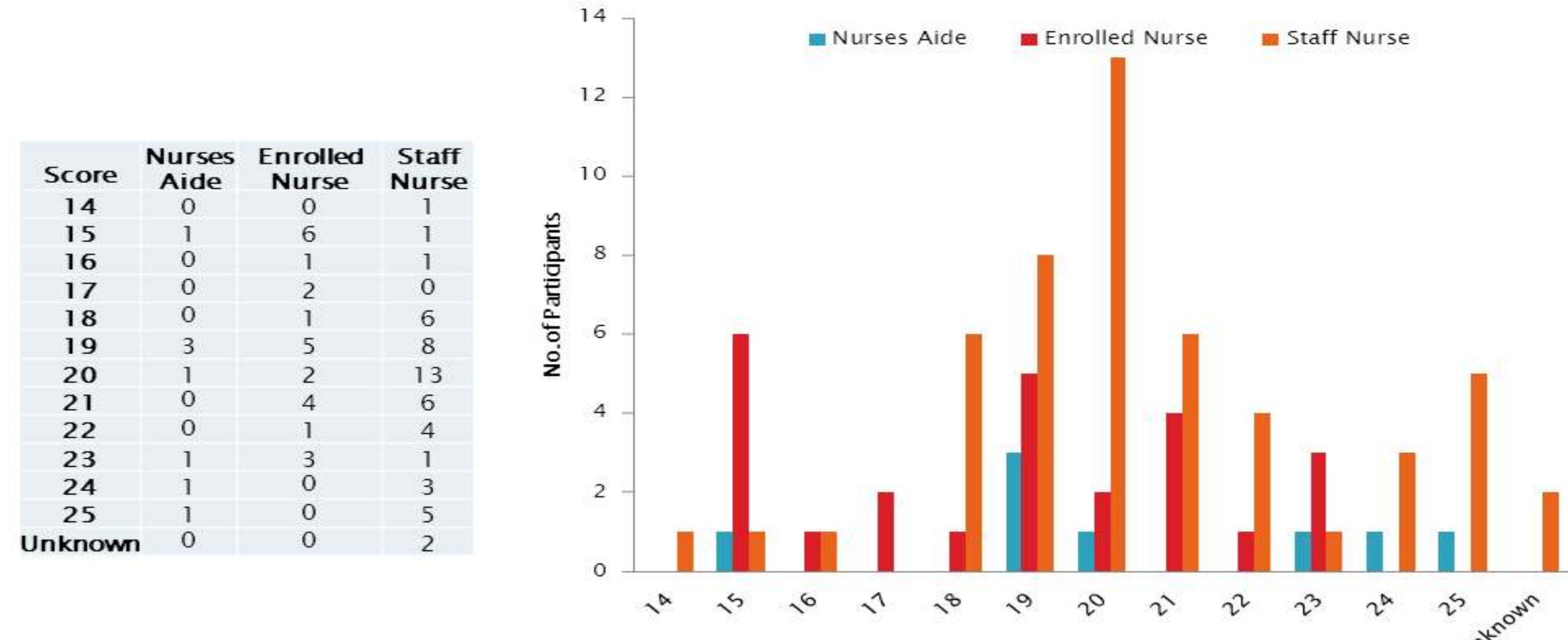

Based on the reflective scoring guided by the rubric, the means scores of RN and EN were 19.5 (range: 15-23/30 marks) and 18.7 (range 15-23/30) respectively. Majority of nurses reflected they had acquired new learning knowledge such as quality control measures in glucose monitoring and storage; use of shorter needle size matters to prevent hypoglycaemia and effects of medications.

There were more than 50 ideas generated to improve the care setting for the question on "what might/should be done better in our care setting". Examples of these ideas include getting junior nursing staff to find out from RNs of whether any pre-meal diabetes medication was administered before patients consume home-cooked foods to prevent surge of blood glucose; establishing diabetes treatment goals for inpatients; gathering patients with diabetes from different wards to conduct self-care management education and provide education on effective nursedoctor communication to discuss about patients presented with persistent trends of hyperglycaemia or hypoglycaemia; providing inpatient diabetic foot screening service and many others.

\section{Discussion}

Reflective evaluation writing rubric could be used as a useful tool to create awareness of learners' to reflect on daily care practice. The evaluation of reflective writing allows educators to solicit valuable feedback that can potentially be used for process and clinical care improvement at the bedside. However, many nurses are still not comfortable to pen down their reflections in writing, and more creative efforts are required to motivate nurses to participate in RELR activities.

\section{Conclusion}

Reflective writing rubric on post diabetes education programme promotes self-reflection and an enriched learning experience for both nurses and educators. The solicited feedback yield valuable ideas that are beneficial for quality improvement and future professional development for the organisation.

\section{Reflective Learning Evaluation Criteria (the rubric)}

\begin{tabular}{|c|c|c|c|}
\hline & 7-10 & $4-6$ & $1-3$ \\
\hline Content quality & $\begin{array}{l}\text { Content clearly relates to the } \\
\text { topic, includes examples. }\end{array}$ & $\begin{array}{l}\text { Content related to the topic, } \\
\text { with at least one example. }\end{array}$ & $\begin{array}{l}\text { Content has little or } \\
\text { nothing to do with the } \\
\text { topic or simple restates the } \\
\text { main concept. }\end{array}$ \\
\hline Critical thinking & $\begin{array}{l}\text { Critical thinking process is } \\
\text { almost always evident in } \\
\text { presented content and ideas } \\
\text { that relate well with the } \\
\text { actual practices. }\end{array}$ & $\begin{array}{l}\text { Critical thinking process is } \\
\text { sometimes evident in } \\
\text { presented content and idea } \\
\text { and sometimes relate with } \\
\text { the actual practice. }\end{array}$ & $\begin{array}{l}\text { Critical thinking process is } \\
\text { rarely evident in presented } \\
\text { content and ideas. }\end{array}$ \\
\hline Structure & $\begin{array}{l}\text { Writing is mostly clear, } \\
\text { concise, and well organized } \\
\text { with good sentence paragraph } \\
\text { construction. Thoughts are } \\
\text { expressed in a coherent and } \\
\text { logical manner. There are no } \\
\text { more than five spelling, } \\
\text { grammar, or syntax errors per } \\
\text { page of writing. }\end{array}$ & $\begin{array}{l}\text { Writing is unclear and or } \\
\text { disorganized. Thoughts are } \\
\text { not expressed in a logical } \\
\text { manner. There are more than } \\
\text { five spelling, grammar, or } \\
\text { syntax errors per page of } \\
\text { writing. }\end{array}$ & $\begin{array}{l}\text { Writing is unclear and } \\
\text { disorganized. Thoughts } \\
\text { ramble and make little } \\
\text { sense. There are numerous } \\
\text { spelling, gammar, or } \\
\text { syntax errors throughout } \\
\text { the response. }\end{array}$ \\
\hline
\end{tabular}

\section{References}

Anice and Renu, G (2015.) Rubrics in Nursing Education. International Journal of Advanced Research, 3 (5). pp. 423-428. ISSN 2320-540

Heidi Goodrich, A. (2005). Teaching with Rubrics: The Good, the Bad, and the Ugly. [online] Available at: http://www.jstpr.org/stable/27559213 [Accessed 2 Jan. 2017]. 